PAPER

\title{
Autobiographical amnesia and accelerated forgetting in transient epileptic amnesia
}

\author{
F Manes, K S Graham, A Zeman, M de Luján Calcagno, J R Hodges
}

J Neurol Neurosurg Psychiatry 2005;76:1387-1391. doi: 10.1136/jnnp.2004.036582

See end of article for authors' affiliations

.....................

Correspondence to:

Professor J R Hodges, MRC

Cognition and Brain

Sciences Unit, 15 Chaucer

Road, Cambridge CB2

2EF, UK; john.hodges@

mrc-cbu.cam.ac.uk

Received 15 January 2004

In revised form

3 January 2005

Accepted 3 February 2005

\begin{abstract}
Background: Recurrent brief isolated episodes of amnesia associated with epileptiform discharges on EEG recordings have been interpreted as a distinct entity termed transient epileptic amnesia (TEA). Patients with TEA often complain of autobiographical amnesia for recent and remote events, but show normal anterograde memory.

Objective: To investigate (a) accelerated long term forgetting and (b) autobiographical memory in a group of patients with TEA.

Methods: Seven patients with TEA and seven age matched controls were evaluated on a range of anterograde memory tasks in two sessions separated by 6 weeks and by the Galton-Crovitz test of cued autobiographical memory.

Results: Patients with TEA showed abnormal long term forgetting of verbal material, with virtually no recall after 6 weeks. In addition, there was impaired recall of autobiographical memories from the time periods 1985-89 and 1990-94 but not from 1995-1999.

Conclusions: TEA is associated with accelerated loss of new information and impaired remote autobiographical memory. There are a number of possible explanations including ongoing subclinical ictal activity, medial temporal lobe damage as a result of seizure, or subtle ischaemic pathology. Future analyses should seek to clarify the relationship between aetiology, seizure frequency, and degree of memory impairment.
\end{abstract}

$\mathrm{T}$ ransient epileptic amnesia (TEA) is a relatively recently delineated syndrome characterised by recurrent brief episodes of amnesia, typically associated with epileptiform discharges arising from the temporal lobes on standard or sleep deprived EEG. ${ }^{1-4}$ Patients with TEA often describe two other types of memory symptom: firstly, the unexpectedly rapid disappearance of memories for events of recent days or weeks, sometimes described as "accelerated forgetting", and secondly, the discovery of large "gaps" in their more remote autobiographical memory; these commonly become apparent when discussing family events and holidays, of which they have no recall. Despite these prominent complaints, patients typically perform normally on standard anterograde memory tests, ${ }^{34}$ and may perform well on remote memory tests. ${ }^{3}$

A number of recent observations in patients with temporal lobe epilepsy suggests that the first symptom reflects an accelerated loss of new information from episodic memory, sometimes referred to as delayed onset amnesia, but this has not been investigated in TEA. ${ }^{56}$ The second symptom may represent a variety of "focal retrograde amnesia". The aims of the current investigation were, firstly, to replicate in a group study the autobiographical amnesia observed in our recent single case report, ${ }^{4}$ and, secondly, to explore the hypothesis that accelerated loss of new material might underlie the unusual pattern of normal performance on standard memory tests in the presence of consistent complaints of poor memory.

\section{METHODS}

\section{Subjects}

Seven right handed patients with TEA ( six men, one woman; mean age 65 years, range 49-79), attending memory clinics in Cambridge $(\mathrm{n}=4)$ and Edinburgh $(\mathrm{n}=3)$, were evaluated with a range of memory tests. These patients represent all of those with TEA seen in these two centres over a 2 year period who were willing to participate. The diagnosis of TEA was made on the basis of the following criteria: (a) there was a history of recurrent witnessed episodes of transient amnesia; (b) cognitive functions other than memory were judged to be intact during typical episodes by a reliable witness; and (c) there was evidence for a diagnosis of epilepsy, provided by either (i) wake or sleep EEG, (ii) the co-occurrence of other seizure types (if their roughly concurrent onset and/or close association with episodes of transient amnesia suggested a connection), (iii) a clear cut response to anticonvulsant therapy, or (iv) a combination of these three factors.

The history of TEA ranged from 6 months to 4 years. At the time of testing, all subjects were free from TEA episodes or ictal phenomena, and were on medication. Table 1 provides demographic, EEG findings (at time of diagnosis), and imaging features. All patients were assessed by a neurologist, neuropsychologist, and experienced neuropsychiatrist. Subjects were excluded if they had a history of transient ischaemic attack or stroke, alcohol misuse, head injury, neurological disease other than that determining inclusion in the study, other major medical illness, psychiatric disease, or evidence of a progressive degenerative disorder. Patients and their spouses were interviewed to look for evidence of premorbid disorders that might predispose to behaviours including psychogenic amnesia. None of the patients was judged to suffer from such disorders, including anxiety, depression, and obsessive compulsive disorder. Seven healthy right handed controls (mean age 64 years; range 50-79) were recruited from the volunteer panel of the MRC Cognition and Brain Sciences Unit. Controls were closely matched with patients for age and estimate of premorbid verbal IQ as assessed by the National Adult Reading Test ${ }^{7}$ the estimated mean (SD) full scale IQ of the patients with TEA was 115.3 (8.5) compared with 110.5 (6.7) for controls. There were no

Abbreviation: TEA, transient epileptic amnesia 
Table 1 Clinical and EEG features of seven patients with transient epileptic amnesia (TEA)

\begin{tabular}{|c|c|c|c|c|c|c|c|c|c|c|c|c|}
\hline Case & $\begin{array}{l}\text { Age } \\
\text { (years) }\end{array}$ & Sex & $\begin{array}{l}\text { History } \\
\text { (duration) }\end{array}$ & $\begin{array}{l}\text { No. of } \\
\text { attacks }\end{array}$ & $\begin{array}{l}\text { Duration } \\
\text { of attacks }\end{array}$ & EEG (routine) & $\begin{array}{l}\text { Other } \\
\text { epileptic } \\
\text { forms }\end{array}$ & $\begin{array}{l}\text { Other } \\
\text { medical } \\
\text { condition }\end{array}$ & Imaging & Medication(s) & MMSE & ACE \\
\hline 1 & 48 & $M$ & 3 years & 4 & $<1$ hour & $\begin{array}{l}\text { Bilateral TL } \\
\text { spikes }\end{array}$ & $\begin{array}{l}\text { Complex } \\
\text { partial } \\
\text { seizures }\end{array}$ & LACS & MRI: normal & $\begin{array}{l}\text { CBZ } 400 \text { mg/day; } \\
\text { lamotrigine } \\
100 \text { mg/day }\end{array}$ & 29 & 98 \\
\hline 2 & 64 & $M$ & 2 years & 7 & 1 minute & $\begin{array}{l}\text { Bilateral TL } \\
\text { spikes }\end{array}$ & $\begin{array}{l}\text { Complex } \\
\text { partial } \\
\text { seizures }\end{array}$ & IHD & $\mathrm{CT}$ : normal & CBZ 600 mg/day & 28 & 96 \\
\hline 3 & 59 & $M$ & 3 years & 6 & $<30$ minutes & Normal & None & IHD & $\begin{array}{l}\text { MRI: vascular } \\
\text { changes }\end{array}$ & $\begin{array}{l}\text { Valproate } \\
100 \mathrm{mg} / \text { day }\end{array}$ & 30 & 98 \\
\hline 4 & 57 & M & 2 years & 6 & $<1$ hour & $\begin{array}{l}\text { Bilateral slow } \\
\text { waves }\end{array}$ & None & IHD & $\begin{array}{l}\text { MRI: vascular } \\
\text { changes }\end{array}$ & CBZ 300 mg/day & 30 & 100 \\
\hline 5 & 46 & M & 1 years & 6 & $<1$ hour & $\begin{array}{l}\text { Focal TL spikes } \\
\text { (right>left) }\end{array}$ & None & None & MRI: normal & CBZ 400 mg/day & 30 & 100 \\
\hline 6 & 59 & $\mathrm{~F}$ & 6 months & 3 & $<1$ hour & $\begin{array}{l}\text { Bilateral TL } \\
\text { spikes }\end{array}$ & None & None & $\begin{array}{l}\text { MRI: vascular } \\
\text { changes }\end{array}$ & CBZ 300 mg/day & 29 & 97 \\
\hline 7 & 69 & M & 4 years & 5 & $<1$ hour & $\begin{array}{l}\text { Bilateral } \\
\text { polyrhythmic } \\
\text { abnormalities }\end{array}$ & $\begin{array}{l}\text { Complex } \\
\text { partial } \\
\text { seizures }\end{array}$ & $\begin{array}{l}\text { Hyper- } \\
\text { tension }\end{array}$ & MRI: normal & CBZ 400 mg/day & 27 & 96 \\
\hline
\end{tabular}

significant differences between groups in terms of age or NART IQ. All testing was undertaken by a single data collector (FM) who was not blinded to the diagnosis.

\section{Illustrative case \\ Case 6}

This 59 year old woman presented in February 2000 with a 6 month history of brief episodes of disorientation during which she would feel muddled and detached from her surroundings. During some attacks, she felt fearful and would question her husband repetitively. The attacks lasted a few minutes. Prior to assessment, she had suffered five such attacks. After commencing sodium valproate therapy the episodes ceased. In addition to the transient episodes of disorientation, she had recently noticed severe retrograde memory loss affecting autobiographical memory stretching back at least a decade. She had been on many trips abroad with her husband, including visits to countries such as Syria and Crete, of which she had practically no recall. She also complained of increasingly forgetting new information such as books and people she has met. Psychiatric assessment revealed no suggestion of mood disturbance, personality disorder, alcohol misuse, or tendency to dissociative behaviours. Neurological examination was normal. A routine EEG showed the presence of bilateral temporal sharp wave discharges with phase reversal. She was enrolled into the present study 12 months after cessation of TEA attacks.

\section{Standard tests}

The Addenbrooke's Cognitive Examination (ACE) and the The Mini Mental State Examination (MMSE) were used as general measurement. The ACE is a 100 point test battery that assesses six cognitive domains. A maximum score of 100 is weighted as follows: orientation (10), attention (8), memory (35), verbal fluency (14), language (28), and visuospatial ability (5). Scores for each of the six domains are calculated separately and their sum gives the composite score on the ACE. The MMSE can be derived from the ACE. Extensive experience with the ACE suggests that it is a reliable instrument for early detection of dementia. ${ }^{8}$

\section{Long term forgetting tests}

Logical memory: story recall and recognition?

Participants were required to listen to two stories and, immediately after hearing each, were asked to recall them from memory. Recall of the stories was re-tested at 30 minutes and 6 weeks. One point was given for each item correctly recalled, maximum possible score of 50. Recognition was tested in a multiple choice procedure using 10 questions for each story (total possible score 20).

\section{Visual reproduction of designs: recall and recognition"}

Participants were shown four drawings for 10 seconds. They were then asked to reproduce them from memory. Recall was tested immediately, then after 30 minutes and 6 weeks, maximum possible score 41 . Recognition was assessed by asking subjects to identify the correct drawing from a set of four.

\section{Autobiographical memory test}

\section{The modified Galton-Crovitz test}

A modified version of the Galton-Crovitz ${ }^{10}{ }^{11}$ technique was used. Subjects were given 10 high frequency nouns (for example, holiday, animal, party) and asked to produce a detailed and specific autobiographical memory related to this word. Each word was presented in three time periods that were chosen in order to explore autobiographical memory for the most recent 15 years (1985-89, 1990-94, and 1995-99) and to uncover patterns of loss/preservation within this era. Two practice items were given before the test list. Subjects were given up to 4 minutes to respond. During the first two minutes, the experimenter provided non-specific prompts (for example, "Tell me more"). If after 2 minutes no episode was produced, subjects were cued by suggesting more concrete possibilities involving the target word (for example, "Have you ever been on a boat?"). The autobiographical episodes produced by the patient were scored for both detail and episodic specificity using a $0-5$ rating scale previously described by a single unblinded rater (FM). ${ }^{12}{ }^{13}$ The maximum score was, therefore, 50 per decade. Administration of the task typically required 45-60 minutes.

\section{Statistical analysis}

The data were analysed using two way analysis of variance with repeated measures in time. Then, simple effects tests were undertaken to study the differences between times for each group and differences between groups for each time, followed by post hoc analyses using Tukey's least significant difference (LSD) test. If data were non-homogeneous in their variance (as measured using the Box test of equality of covariance matrices, Mauchly's test for sphericity, and Levene's test of equality of error variances) the logarithm of the raw scores was calculated. ${ }^{14}$ In all instances, original 


\begin{tabular}{|c|c|c|}
\hline & Controls & Patients \\
\hline \multicolumn{3}{|l|}{ Logical memory } \\
\hline \multicolumn{3}{|l|}{ Recall } \\
\hline Immediate & $26.3(4.7)$ & $27.4(6.7)$ \\
\hline 30 minutes & $24.0(5.0)$ & $22.7(9.5)$ \\
\hline 6 weeks & $11.8(5.0)$ & $1.7(2.3)$ \\
\hline \multicolumn{3}{|l|}{ Recognition } \\
\hline 30 minutes & $16.8(1.5)$ & $16.5(1.7)$ \\
\hline 6 weeks & 15.0 (3.6) & $8.0(7.6)$ \\
\hline \multicolumn{3}{|c|}{ Visual reproduction } \\
\hline \multicolumn{3}{|l|}{ Recall } \\
\hline Immediate & $30.0(5.7)$ & $24.3(3.7)$ \\
\hline 30 minutes & $18.7(9.5)$ & $14.4(6.8)$ \\
\hline 6 weeks & $3.3(3.9)$ & 0 \\
\hline \multicolumn{3}{|l|}{ Recognition } \\
\hline 30 minutes & $3.7(1.1)$ & $4.7(0.7)$ \\
\hline 6 weeks & $3.3(0.9)$ & $3.7(1.4)$ \\
\hline
\end{tabular}

non-transformed data are presented in tables and figures. Software used was SPSS 10.0. Significance levels were set at $\alpha<0.05$.

\section{RESULTS}

Table 1 displays the scores on the ACE and MMSE. There was no statistically significant difference between the TEA and control groups on either test and all patients with TEA performed above the cutoff for dementia on both.

\section{Long term forgetting tests}

\section{Logical memory: recall and recognition}

To take into account a lack of homogeneity in the data across groups, logarithms were calculated for recall scores (table 2). Analyses of changes over time showed significant differences in both groups (controls: $F_{(2,24)}=7.562, \mathrm{p}<0.01$; TEA: $\left.F_{(2,24)}=81.267, \mathrm{p}<0.0001\right)$. Post hoc tests revealed no significant difference between recall scores for immediate and 30 minutes, but a significant decrement between these two time periods and 6 weeks in both groups. Intergroup analyses revealed no differences between controls and patients with TEA for immediate $\left(F_{(1,36)}=0.016, \mathrm{p}>0.90\right)$ and 30 minute recall $\left(F_{(1,36)}=0.163, \mathrm{p}>0.60\right)$, but a highly significant difference between groups at 6 weeks $\left(F_{(1,36)}=53.95, \mathrm{p}<0.0001\right)$ confirming a pattern of accelerated forgetting. This difference is illustrated by considering the raw recall scores of individual controls and patients with TEA (fig 1); none of the controls scored at floor (individual scores: 5, 7, 8, 14, 15, 17, 17) whereas four patients scored 0 at 6 weeks and the other three scored 3, 4, and 5, respectively. There was, therefore, virtually no overlap between the controls and TEA cases.

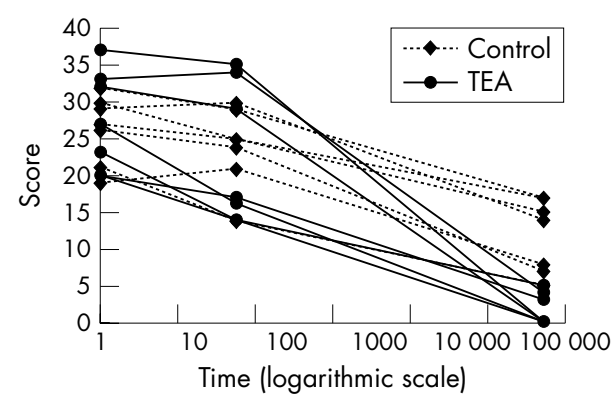

Figure 1 Individual control and TEA subjects' scores recall of stories (logical memory) over time (logarithmic scale).

$\begin{aligned} & \text { Table } 3 \text { Data from Galton-Crovitz test for } \\
& \text { three time periods }\end{aligned}$
\begin{tabular}{lll}
\hline $\begin{array}{l}\text { Galton- } \\
\text { Crovitz test }\end{array}$ & Controls & Patients \\
\hline $1985-1989$ & $15.6(4.1)$ & $15.6(4.1)$ \\
$1990-1994$ & $33.0(9.6)$ & $14.6(10.8)$ \\
$1995-1999$ & $35.3(8.2)$ & $28.0(11.8)$ \\
\hline
\end{tabular} Results are mean (SD).

A similar pattern emerged on analysis of the recognition scores (it was not necessary to take logarithms to this variable). Analysis of time effects for each group revealed no significant difference between scores obtained in the two time periods for the control group $\left(F_{(1,12)}=0.70, \mathrm{p}>0.50\right)$. By contrast, there was a highly significant difference between the scores obtained for the patients with TEA at 30 minutes and 6 weeks $\left(F_{(1,12)}=14.39, \mathrm{p}<0.0001\right)$. Intergroup comparisons showed no differences between groups at 30 minutes $\left(F_{(1,24)}=0.03, \mathrm{p}>0.80\right)$, but poorer recognition of stories at 6 weeks for the TEA group $\left(F_{(1,24)}=8.89, \mathrm{p}<0.05\right)$, again indicating accelerated forgetting over 6 weeks in the TEA group.

\section{Visual reproduction: recall and recognition}

For the analysis of the recall component, we had to eliminate the data from the 6 week testing session because all of the patients with TEA scored 0 . There was a significant difference between immediate and 30 minutes' recall in both control $\left(F_{(1,12)}=15.82, \quad \mathrm{p}<0.0001\right)$ and TEA $\left(F_{(1,12)}=12.07\right.$, $\mathrm{p}<0.001)$ groups. Intergroup comparisons revealed no significant differences between groups at immediate $\left(F_{(1,24)}=2.49, \mathrm{p}>0.10\right)$ nor at 30 minutes $\left(F_{(1,24)}=1.40\right.$, $\mathrm{p}>0.25)$.

For the recognition component of the task, both controls and TEA groups obtained near perfect scores (table 2). Analysis of the effects of time showed no significant difference for the control group $\left(F_{(1,12)}=1.12, \mathrm{p}>0.30\right)$ but a difference was evident in the patients with TEA $\left(F_{(1,12)}=6.12, \mathrm{p}<0.01\right)$. Notably, however, comparison at each time period did not find differences between groups at 30 minutes $\left(F_{(1,24)}=3.03, \quad \mathrm{p}>0.10\right)$ nor at 6 weeks $\left(F_{(1,24)}=0.55, \mathrm{p}>0.40\right)$. There was therefore no evidence of accelerated loss in the TEA group.

\section{Autobiographical memory test}

The modified Galton-Crovitz test

The results are shown in fig 2 and table 3. Raw scores were used because tests of homogeneity indicated appropriate variance. Analyses of the differences across time showed no significant effect in the control group $\left(F_{(2,24)}=2.64, \mathrm{p}>0.09\right)$, but a highly significant difference for the TEA group

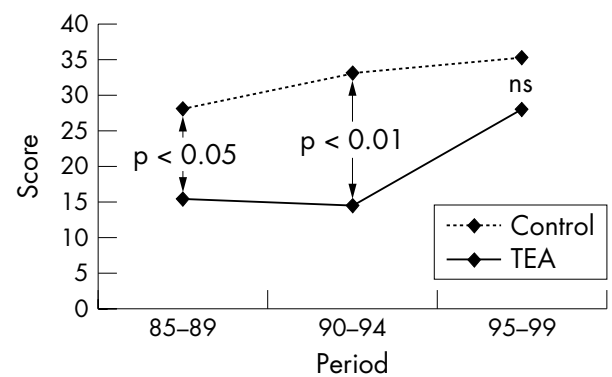

Figure 2 Performance on the Galton-Crovitz test of cued autobiographical memory showing scores for three time periods 198589, 1990-94, and 1995-99 in TEA and control groups. 
$\left(F_{(2,24)}=11.10, \mathrm{p}<0.001\right)$. Post hoc tests in the patients confirmed that the effect was generated by the most recent time period in that there was no significant difference between time periods $85-89$ and $90-94$, but there was a significant difference between these periods and the time period 95-99. In support of this, inter-group comparisons showed a difference between control and TEA groups for the older two time periods, $85-89\left(F_{(1,36)}=5.46, \mathrm{p}<0.05\right)$ and 90-94 $\quad\left(F_{(1,36}=11.74, \quad \mathrm{p}<0.01\right) \quad$ but not for $95-99$ $\left(F_{(1,36)}=1.84, \mathrm{p}>0.20\right)$.

\section{DISCUSSION}

We have shown for the first time, in a group study, that patients with TEA exhibit clear deficits in autobiographical memory, as measured by the Crovitz-Galton method, and a pattern of accelerated forgetting for verbal material.

These findings have both clinical and theoretical implications. Clinically, most formal evaluations of memory in patients with TEA, and indeed epilepsy in general, have assessed retention of new memory after delays of 3040 minutes. The present study shows that an individual may perform well on standard tests of new learning, but have marked difficulty retrieving information over a more extended period (6 weeks). Our findings are similar to those of a recent study in which patients with typical temporal lobe epilepsy arising from a left sided focus were shown to have accelerated loss of verbal memory over 8 weeks. ${ }^{6}$

Accelerated forgetting in our patients was less evident on tests of visual memory; although the performance of the patients with TEA was worse than that of controls on the recall condition of the visual reproduction task, there was no significant group by time interaction to indicate accelerated forgetting. Examination of the group's scores indicates that this was almost certainly due to the fact that controls had very little recall of the pictures in the visual recognition memory test after 6 weeks, creating problems with floor effects in both groups. On the recognition based test of visual memory, the performance of both controls and TEA groups was, by contrast, extremely good, making it difficult to exclude potential impairment in the TEA group being due to ceiling effects. It is possible, therefore, that the memory deficit seen in our patients extends to verbal and visual material, but at present we have demonstrated effects for verbal information only.

We have shown that the frequent complaint of amnesia for recent holidays and family events represents a true deficit that can be measured using appropriate instruments. When patients' complaints of memory problems are not readily explicable, psychogenic explanations are often invoked. Although we cannot totally exclude psychogenic explanation for the autobiographical memory loss, there are no positive reasons for suspecting this in the face of normal systematic psychiatric assessment. The fact that patients with TEA complain of loss of autobiographical memory was observed by Kapur ${ }^{1}$ in his seminal description, although it has been difficult to document this deficit on formal tests, perhaps due to the patchy nature of the loss and the insensitivity of some methods of assessing autobiographical memory. For instance, in the widely used Autobiographical Memory Interview, ${ }^{15}$ subjects are asked to relate just three episodes from each of three broad eras (school days, early adulthood, and recent life), wherease the Galton-Crovitz method requires subjects to recall a number of incidents from specified time periods. The difference in technique probably explains the apparent discrepancy between our current and previous group study, ${ }^{3}$ in which seven of the 10 patients with TEA reported a patchy loss of recall for salient episodes from their recent past, yet, despite these complaints, performed normally on tests of anterograde memory and on the Autobiographical Memory Interview.

The present investigation was stimulated by our single case study of a 68 year old man with TEA, who reported very striking autobiographical memory gaps. ${ }^{13}$ The man underwent a battery of tests of anterograde and remote memory, including knowledge of people, events, and his own autobiography. He was unable to evoke detailed recollections from a larger part of his life. In contrast, he performed well on tests of new learning and general knowledge, and had good personal semantic information about his past. We have replicated this finding in a group study, and shown, in addition, that such patients have accelerated forgetting or what has sometimes been termed delayed onset amnesia. ${ }^{16}$ As all of the patients were receiving anti-convulsant medication, we are unable to exclude this as a possible contributing factor, as memory complaints and deficits on formal testing are well recognised side effects of such medication. ${ }^{17-19}$ There is, however, no evidence that these drugs produce accelerated forgetting or disproportionate autobiographical amnesia.

What then is the underlying pathological process causing the accelerated forgetting and retrograde amnesia? The causal inter-relationships between attacks of epileptic amnesia and these two phenomena is unclear. We shall consider each in turn.

Firstly, the accelerated forgetting: we have suggested previously that recurrent seizures play a key role, but the fact that the current patients were apparently in remission casts some doubt upon this conclusion. While subclinical seizure activity might still be present, it is also possible that the episodes of TEA and accelerated forgetting are independent results of a common underlying pathology. Patients with TEA have a high rate of vascular risk factors, and nonspecific ischaemic type changes are frequently present on MRI. Of our seven patients, six had clinical risk factors for cerebrovascular disease and/or vascular changes on MRI (table 1). Accelerated forgetting has not been reported in the context of mild cerebrovascular disease, but this possibility is worthy of further investigation. Alternatively, episodes of TEA might themselves give rise to structural damage within the hippocampus or related structures, which could disrupt long term consolidation.

Secondly, the autobiographical amnesia: impairment of encoding by clinical or subclinical seizures and the effects of accelerated forgetting may account, in part, for the autobiographical memory loss that occurs in TEA. However, this is unlikely to be the whole explanation as the autobiographical memory loss often extends back over two or more decades, long before the clinical onset of TEA. According to the standard view of memory consolidation, extensive retrograde amnesia is likely to be the result of damage to cortical memory representations or, more plausibly, the links between individual sensory elements that constitute an autobiographical episode. ${ }^{20}$ Recent studies of patients with medial temporal pathology have suggested that the hippocampal formation has a life long role in the storage of autobiographical memories. ${ }^{21}$ It is plausible therefore that medial temporal damage, whether occurring as a result of recurrent seizures and/or underlying subtle vascular damage, could result in both accelerated forgetting and retrograde amnesia. Further work investigating the relationships between seizure frequency, EEG activity, structural changes in the temporal lobes, and the severity of accelerated forgetting and autobiographical memory loss, is required to clarify these issues.

At a clinical level, the syndrome of TEA is clearly identifiable and has a unique neuropsychological profile. In our experience, patients most often present complaining of islands of memory loss that become apparent when discussing holidays or family events. We now ask patients with 
suspected TEA if they have gaps in their autobiographical memory, and especially about recall of holidays and other salient personal events. This is not, we would argue, because of the unique status of such events, but rather because it reflects the patchy nature of the remote memory deficit and the vulnerability of singular events. It is unlikely that a single week missing from everyday life would be noticed, owing to the repetitive nature of most day to day activities. In contrast, the loss of memory for last year's holiday brings the retrograde memory loss into sharp relief. If questioned appropriately, many patients are also aware of the accelerated forgetting. Several patients volunteered that they can recall new episodes (such as conversations with friends, the content of books or films) for a few days but not after a month. Such symptoms could be the basis of a useful clinical assessment instrument. The ictal events are often rather minor, and their brevity and diurnal pattern may mask their significance.

Transient global amnesia (TGA) is distinguished from TEA by a number of features. Episodes of TGA typically last for hours with gradual resolution. They frequently follow physical exertion or emotional stress, and are rarely recurrent. ${ }^{22}$ During the attack, both patients with TGA and those with TEA are densely amnesic and repetitive, but in TGA the retrograde amnesia is temporally limited. ${ }^{11}$ In TEA, by contrast, complaints of retrograde memory loss may predominate. Recovery from TGA is protracted, with minimal, if any, persistent cognitive impairment, but TEA appears to be associated with both accelerated forgetting of new material and an extensive loss of remote personal memory.

\section{ACKNOWLEDGEMENTS}

This research was supported by the Medical Research Council, UK.

\section{Authors' affiliations}

F Manes, M de L Calcagno, Cognitive Neurology Division, Department of Neurology, Raul Carrea Institute for Neurological Research (FLENI), Buenos Aires, Argentina

K S Graham, J R Hodges, MRC Cognition and Brain Sciences Unit, Cambridge, UK

A Zeman, Department of Clinical Neurosciences, University of Edinburgh, Western General Hospital, Edinburgh, UK

J R Hodges, University of Cambridge Neurology Unit, Addenbrooke's Hospital, Cambridge UK

Competing interests: none declared

\section{REFERENCES}

1 Kapur N. Transient epileptic amnesia - a clinical update and a reformulation. J Neurol Neurosurg Psychiatry 1993;56:1 184-90.

2 Kopelman MD, Panayiopoulos CP, Lewis P. Transient epileptic amnesia differentiated from psychogenic "fugue": neuropsychological, EEG, and PET findings. J Neurol Neurosurg Psychiatry 1994;57:1002-4.

3 Zeman AZ, Boniface SJ, Hodges JR. Transient epileptic amnesia: a description of the clinical and neuropsychological features in 10 cases and a review of the literature. J Neurol Neurosurg Psychiatry 1998;64:435-43.

4 Mendes MCF. Transient epileptic amnesia: an underdiagnosed phenomenon? Three more cases. Seizure 2002;11:238-42.

5 O'Connor M, Sieggreen MA, Ahern G, et al. Accelerated forgetting in association with temporal lobe epilepsy and paraneoplastic encephalitis. Brain Cogn 1997;35:71-84.

6 Blake RV, Wroe SJ, Breen EK, et al. Accelerated forgetting in patients with epilepsy. Evidence for an impairment in memory consolidation. Brain 2000;123:471-83.

7 Nelson $\mathrm{H}$, Willison J. The national adult reading test (NART). Windsor: NFERNelson, 1991.

8 Mathuranath PS, Nestor P, Berrios GE, et al. A brief cognitive test battery to differentiate Alzheimer's disease and frontotemporal dementia. Neurology 2000;55:1613-20.

9 Wechsler DA. Wechsler memory scale - revised. San Antonio: Psychological Corporation, 1987.

10 Crovitz HF, Schiffman H. Frequency of episodic memories as a function of their age. Bull Psychonomic Soc 1974;4:517-18.

11 Hodges JR, Ward CD. Observations during transient global amnesia: a behavioural and neuropsychological study of five cases. Brain $1989 ; 112: 595-620$.

12 Graham KS, Hodges JR. Differentiating the roles of the hippocampal complex and the neocortex in long-term memory storage: evidence from the study of semantic dementia and Alzheimer's disease. Neuropsychology 1997;11:77-89.

13 Manes F, Hodges JR, Graham KS, et al. Focal autobiographical amnesia in association with transient epileptic amnesia. Brain 2001;124:499-509.

14 Winer BJ, Brown DR, Michels KM. Statistical principles in experimental design, 3rd ed. New York: McGraw-Hill Book Company, 1991.

15 Kopelman MD, Wilson BA, Baddeley AD. The autobiographical memory interview. Bury St Edmunds: Thames Valley Test Company, 1990.

16 Mayes AR, Roberts N. Theories of episodic memory. Philos Proc R Soc B 2001;356:1395-408.

17 Motamedi GK, Meador KJ. Antiepileptic drugs and memory. Epilepsy Behav 2004;5:435-9.

18 Bergin PS, Thompson PJ, Baxendale SA, et al. Remote memory in epilepsy. Epilepsia 2000;41:231-9.

19 Helmstaedter C, Kurthen M. Memory and epilepsy: characteristics, course, and influence of drugs and surgery. Curr Opin Neurol $2001 ; 14: 211-16$

20 Hodges JR, Graham KS. Episodic memory: insights from semantic dementia. Philos Trans R Soc Lond B Biol Sci 2001;356:1423-34.

21 Nadel L, Samsonovich A, Ryan L, et al. Multiple trace theory of human memory: computational, neuroimaging and neuropsychological results. Hippocampus 2000;10:352-68.

22 Hodges JR, Warlow CP. Syndromes of transient amnesia: towards a classification. A study of 153 cases. J Neurol Neurosurg Psychiatry 1990;53:834-43 